\title{
Huelga de chinos: el gran conflicto laboral olvidado de Costa Rica
}

\begin{abstract}
Alonso Rodriguez Chaves*
“...Esta clase de inmigración viene sola, está formada por lo general del deshecho de las naciones, de aventureros que acuden á los puertos y emigran en la primera nave que zarpa. Los coolies y los chinos que en lugar de aportar energía y prosperidad nos inundan de asquerosas enfermedades y de crímenes espantosos..."

Mariano Montealegre, $1895^{1}$

“....es gente que por su raza, sus hábitos de vida y espiritu aventurero e inadaptable a un ambiente de orden y de trabajo, serían para el país motivo de "degeneración fisiológica y elementos propicios para el desarrollo de la holganza y del vicio”.
\end{abstract}

Ascensión Esquivel, $1898^{2}$

\section{RESUMEN}

En la historiografía costarricense se tiende no a omitir sino a reducir el conflicto laboral ocurrido en 1874, entre los trabajadores chinos y la empresa responsable de la construcción de la vía del ferrocarril al Atlántico, a simple motín. Así, el artículo presenta como propósito dilucidar, por sus características, dicho conflicto laboral, como la primera huelga que se tenga en Costa Rica. Igualmente, se han de analizar los efectos que tuvo al nivel de pérdidas de vidas humanas y las

\footnotetext{
* Encargado de Cátedra de Historia de la Universidad Estatal a Distancia. Arodriguez uned.ac.cr

1. Montealegre, Mariano. “La inmigración en Costa Rica.” La República. San José, Costa Rica. 1895.

2. ANCR - Serie Congreso: 9548. Nota: Cuando se cite siglas ANCR entiéndase Archivo Nacional de Costa Rica.
} 
consecuencias que trajo al país al nivel internacional. Por las características del conflicto se presenta como el antecedente de los movimientos reivindicativos que sucedieron en años subsiguientes, y a su vez como homenaje a todos y todas que luchan por la dignidad del ser humano.

Palabras clave: Trabajadores chinos, ferrocarril al Atlántico, huelga, patrono, contrato y conflicto laboral.

\begin{abstract}
The costarrican history tends not to omit but to reduce the labor dispute occurred in 1874 between the Chinese workers and the responsible business to build the railroad to the Atlántico, a simple... Hence, the article has a purpose to elucidate, through his own characteristics, that labor dispute as the first strike occurred in Costa Rica. Likewise, there are analyzed the effects of the lost of human lives, and the international consequences that came up to the country. According to the conflicts' features, it is presented as an antecedent of the protest movements which took place in the subsequent years, and at the same time as a homage to all and every person who struggles for the human beings' dignity.
\end{abstract}

Keywords: Chinese workers, railroad to the Atlántico, strike, boss, contract, labor dispute.

\section{A manera de introducción}

Los movimientos de población a través del espacio geográfico mundial, han constituido una constante en la historia de la humanidad. Por su extensión en el tiempo y espacio, se percibe como un fenómeno complejo. Principalmente, cuando se parte de que el migrante suele por lo general ser vulnerable a condiciones de pobreza, desprotección y explotación laboral en las diferentes realidades económicas-sociales en que figura.
Siguiendo dicha premisa, nace el interés en estudiar la dinámica sociolaboral de los trabajadores chinos forjada alrededor de la cotidianidad de la construcción de la vía del ferrocarril al Atlántico, a finales de siglo XIX. La idea se fortalece, cuando diferentes fuentes revelan, que el grupo en cuestión fue marginado de prerrogativas y garantías que gozaron otros trabajadores en el mismo contexto, producto en gran medida, de diversas asunciones inducidas por algunos sectores oficiales, que difundieron en el 
imaginario colectivo costarricense, al chino como estigma social negativo, elemento "extraño" y "almas muertas" al desarrollo natural del país. (ANCR- Serie Gobernación: 12043, 1897 y ANCR - Serie Gobernación: 7963. Folio 3).

En este nivel, el presente estudio acapara atención especial, al intentar dilucidar, más que su condición de inmigrante y extranjero "no deseado", su condición de trabajador. Por ende, hay un conjunto de medidas tomadas, para contrarrestar los efectos negativos de su deplorable situación laboral. Particularmente, el uso que hicieron de la huelga para tratar de imponer la aceptación de las condiciones laborales a los patronos.

Si bien otrora la huelga era recurso bastante conocido y utilizado como derecho de las clases trabajadoras en estados de legislación social avanzada, para hacer valer derechos $\mathrm{y}$ otras reivindicaciones laborales, lo cierto es que la huelga retoma importancia como tema de estudio. Cuando los trabajadores chinos decidieron, de común acuerdo, hacer cese de las tareas encomendadas en 1874, se estaba ante la presencia eminente del primer conflicto obrero patronal que se tenga noticia en Costa Rica. Mismo que en la historiografía costarricense se tiende a ocultar sino a desdibujar al nivel de simple motín de unos cuantos trabajadores.

En virtud de lo anterior se presentan antecedentes y detalles de las condiciones que imperaron y que afectaron directamente a trabajadores chinos; que a la postre desencadenaron en uno de los conflictos laborales más apoteósicos y olvidados en páginas de la historia costarricense.

\section{Antecedentes}

Durante el siglo XIX, China se vio asediada por una prolongada crisis interna. No obstante, la voracidad de potencias extranjeras y la nueva estructura económica implantada por la expansión capitalista, ayudó a que la sociedad china sucumbiera por completo. (Revista de la Organización Internacional para la Migración (OIM) 1995:10).

El nivel de vida de la población sufrió tales presiones, que dio cabida a diversos movimientos reivindicativos. Al respecto se decía que...

"Nadie ignora que la China es por excelencia el país donde las insurrecciones pueden durar muchos años y sublevar centenares de miles de hombres." (Verne, 1996: 130).

Ante un ambiente turbio como el anotado, una importante cantidad de la población china comenzó a ser arrastrada por un largo fenómeno global, caracterizado por el movimiento de trabajadores, capital y tecnología que sobrepasan las fronteras nacionales, para explotar recursos materiales en varios lugares del mundo. Esto por cuanto, la expansión, 
la internacionalización económica y la industrialización de occidente, habían derribado todas las barreras nacionales y su implantación exigía movilización global de mano de obra barata (Brinley:1991).

Así las cosas, muchos trabajadores chinos desesperados se vendían y entregaban a contratistas (Martínez, 1993: 397). En años posteriores, con apelativo de "culis", fueron dirigidos a colonias británicas, francesas, holandesas, Estados Unidos y a países del "Nuevo Mundo", para sustituir la mano de obra esclava por otra de colorido menos acentuado (Mesa, 1967: 166):

"Los llamaban culis, los llamaban indistintamente, culis chinos y culis indios, porque culi es una palabra que en la India significa algo así como una persona que hace oficios muy bajos, todavía en la India sigue siendo, el trabajador que está ahi en las estaciones, el que jala las maletas, es un trabajador humilde, eso es el culi.

Cogieron ese nombre y se lo aplicaron a todos los que tenían contratos, o sea no es una palabra china, más bien es de origen indio." (Chen, 1999).

Teniendo en cuenta esta condición, no fue extraño que la masificación y las condiciones deplorables en que viajaban los trabajadores chinos, produjeran frecuentes insurrecciones y conflictos dentro de las embarcaciones. Tal y como sucedió en la embarcación española "Encarnación", donde 92 de los 324 "pasajeros" y dos miembros de la tripulación perdieron la vida en agosto de 1860 . Igualmente, se reseña caso similar en 1882:

"Abordo, cuando intentaron cobrar
su libertad, el cañón que barría la cu-
bierta y la tripulación decidida y ar-
mada hasta los dientes, sofocaba los
motines prodigando la muerte de una
manera espantosa..." (Chen, 1999).

Ante ese panorama, se inició un proceso de conversación entre autoridades del gobierno de India, China y Gran Bretaña, para convenir condiciones y contrataciones más justas de los trabajadores. Producto de ello, la Reina Isabel II de Inglaterra dictó Real Orden, que exhortaba a "humanizar este comercio" y el "buen trato que la religión y la humanidad exigen". Así advierte, que en caso de incumplimiento, se procediera a la suspensión del envío de más trabajadores. (Pérez, 1974: 145).

Si bien fue trascendental la participación de Gran Bretaña en tratar de humanizar el comercio y tráfico de culís, también lo fue la de los sindicatos. En especial cuando propiciaron, incesantemente, una legislación con mayores garantías para los trabajadores en el lugar donde se les contratara. En particular, mejores garantías en materia de transporte, salario, jornada de trabajo, alimentación y vivienda (Gómez: 35; Martínez y Reynoso: 398). 
Ahora, sea cual sea la forma en que los trabajadores chinos fueran contratados, lo cierto es que durante el siglo XIX produjeron un "equilibrio", al proveer de mano de obra a diferentes países, en especial a Estados Unidos de América, donde ayudaron a explotar ricos yacimientos auríferos en California ${ }^{1}$, a construir la vía férrea en Sierra Nevada y, más tarde, en plantaciones de caña y arroz en la isla de Hawaii (Kim: 100).

Es claro que tanto la frontera en expansión y vida económica pujante fueron las razones que convirtieron a dicho país en importante foco de atracción, aunque la situación para los trabajadores fue bastante ominosa. Así, decenas fueron cruelmente asesinados en los Ángeles (1871); Rock Springs, Wyoming (1886), entre otros lugares (Chan: 50). Todo esto sin dejar de mencionar, las severas medidas de restricción que se impusieron a la "importación" de mano de obra china, bajo el pretexto de proteger a los nacionales del abaratamiento de sus salarios (Mon: 248).

$\mathrm{Al}$ respecto, Irving Howe apunta, que detrás de los móviles para proteger a los trabajadores locales de la supuesta competencia desleal, se ocultaba el espíritu xenófobo, manifestado con estereotipos negativos, que señalaban a los chinos como trabajadores de mala calidad, en tanto se les consideraba:

“...inmigrantes idiotas, insanos, vagabundos o personas que se pudieran convertir en una carga pública, aquellos con enfermedades contagiosas, aquellos procesados por una felonía u otro acto infame que implicara una moral dudosa, polígamos y también a cualquier persona cuyo tiquete o pasaje fuese pagado con el dinero de otro, o que es asistido para que emigre, a menos de que sea probado en forma positiva, en una investigación especial, que tal persona no pertenece a ninguna de las clases excluídas, o a la clase de contrato laboral excluida en 1885." (Howe, 1976: 91).

Consecuentemente, miles de chinos fueron rechazados y expulsados de Estados Unidos, lo cual les obligó a reemigrar hacia países cercanos como Cuba, Perú, Panamá, México, Colombia, Chile, Venezuela, Guatemala, El Salvador, Ecuador, Honduras, Costa Rica, entre otros del continente; que se encontraban

1. El oro de California se descubrió el 24 de enero de 1848 en Colonna, casi 100 kilómetros al este del fuerte Sutter. Este hallazgo ocasionó grandes migraciones de aventureros de todas partes del mundo. 
asediados de insuficiente mano de obra (Mörner,1978: 57).

\section{Situación de los trabajadores chinos en Costa Rica}

En Costa Rica, inmersa en un régimen de capitalismo agrario, en el que se consolida su inserción definitiva al mercado mundial, reaparece la necesidad de construir la vía del ferrocarril al Atlántico, que enlazará a Puerto Limón con Puerto Caldera, en el lado Pacífico (Decreto Ejecutivo No. LXII: 4 de 11 de 1825).

Si bien fructificó el contrato de construcción durante el gobierno del General Tomás Guardia, la magnitud del proyecto y la situación de empleo dada en el interior del país, dejó de manifiesto la insuficiente mano de obra existente. En razón, se les permite a los empresarios Hubbe y Grytzell, en compañía de Enrique Meiggs Keith, finalmente, la contratación de 653 trabajadores chinos en 1872 . Esto por las buenas experiencias que habían tenido dichos empresarios con ese tipo de trabajadores en Perú y Chile (ANCR - Serie Fomento: 217. Folio 1).

Para el ingreso del citado grupo, al gobierno se le obligó velar por el buen trato que se debía dar a los chinos, con un pliego de garantías y prerrogativas, de las cuales disfrutarían los trabajadores en su condición de contratados:
1. Obligados a trabajar con Keith, Hubbe y Grytzell o a quienes estos traspasen los respectivos contratos, diariamente por un término de 8 años consecutivos a partir de la fecha de embarque.

2. Los contratistas están obligados a darles alimento sano y suficiente, habitación cubierta, tres vestidos de manta y una cobija y cinco pesos al año en moneda del país por cada mes de trabajo,

3. Jornada de trabajo hasta de 12 horas diarias,

4. Cada año se les concedía tres días de fiesta para sus funciones religiosas

5. En caso de enfermedad se les daría gratis la asistencia médica

6. Keith y sus socios vendían los chinos a razón de 350 pesos cada uno, cobrando la mitad en el momento de entregar el chino, y el resto tres meses después con un interés de $1 \%$ mensual. Si no se cumplía el pago, Keith y compañía podían retirar los chinos y de nuevo venderlos por el resto de la deuda, con derecho a cobrar daños y perjuicios.

El gobierno, en resolución del 12 de abril de 1872, acordó:

1. Conceder la prima de 30 pesos por chino introducido al país "siempre que después de tres meses de permanencia en este país acrediten en forma que son inteligentes 
para los trabajos de agricultura, esto es de plantaciones y ganadería a que se dediquen,

2. El gobierno no puede intervenir de manera alguna en los contratos que se celebren, dejando hacer a las partes lo que más convenga a sus intereses,

3. El gobierno garantizaba a los trabajadores chinos y a las autoridades de la china que los nacionales chinos gozarían de las mismas garantías individuales que los costarricenses, que serían iguales ante la ley a los demás habitantes del país y que se les administraría cumplida justicia por los tribunales, sea respecto de su contrato de jornal o alquiler de su trabajo o sea por cualquier otro motivo." (De la Cruz, 1984).

Bajo el supuesto de una serie de condiciones indicadas, el ingreso de los trabajadores se concretó, finalmente, hasta 1873. Ya en territorio nacional, los centenares de chinos fueron conducidos a los Campamentos $3,4,5$, de la III División de la construcción de la vía del ferrocarril, en particular, la zona que comprendía del centro de Cartago a la Angostura (ANCR- Serie: Fomento 1634, f. 303, 28 de mayo de 1873. Serie: Fomento doc: 1531, f.114-115, dic 1873; Serie: Fomento 1634, f. 295, 15 de mayo 1873). Una vez ubicados en los sitios de trabajo, se les asignó labores específicas a la formación de terraplenes, que servían de base para la colocación de los durmientes y rieles (ANCR-Serie Gobernación: 34334). Además por su reconocida experiencia en labores propias de manipulación de explosivos:

"En los peligrosos trabajos de Fajardo murieron un inglés y dos chinos, por accidentes puramente casuales, pues en aquel lugar aunque se ha empleado mucha pólvora y dynamite(sic), las explosiones causadas por esos poderosos auxiliadores no han causado ningún daño, debido á que son bien manejados" (El Ferrocarril, 11 de setiembre de 1873: 22)

En general, la incorporación de esta fuerza laboral al país, resultó de gran beneficio y alivio de consideración para los empresarios que urgían de "brazos auxiliares". (ANCR- Serie Policía: 5651). Sin embargo, llama la atención, el hecho de que, pese al importante rol que jugaron, del total de trabajadores que habían ingresado, apenas 236 se mantenían en el proyecto solo un año después (León: 6). Entre otras razones esto se explica, porque....

"Los contratos que sirvieron de base para la traída de esa gente (chinos), los colocaba en una situación comparable a la de los negros de época de la esclavitud. El trato que recibieron fue sumamente grosero, el trabajo muy duro, alimentación pésima, la jornada de trabajo muy 
larga y el salario miserable, apenas la sexta parte de lo que ganaba un peón costarricense. Además se les castigaba con frecuencia y muchos perdieron la vida en accidentes laborales, por el clima y las enfermedades, o por la matanza de 1874." (Fallas: 214).

En asocio con la idea anterior, y otras fuentes estudiadas, la llegada de ese grupo de trabajadores se inserta en uno de los capítulos más oscuros de la historia costarricense, al comprenderse dentro de un ambiente de constante violación de derechos y pésimas condiciones laborales que tuvieron que enfrentar. Aunado a la oposición y a la discriminación oficializada que proveían a los trabajadores chinos una serie de situaciones incómodas como las que se indican a continuación (ANCR - Serie Gobernación: 34334 y Oliva, 1992: 269):

"... a cada momento son conducidos á las cárceles con perjuicio de sus patrones, y solamente se defienden de los incesantes ataques de los muchachos que se divierten en atormentar á esos seres desgraciados por todos títulos, y que por las circunstancias ecepcionales que los acompañan, debieron ser amparados más bien hostilizados por las autoridades de Polícia.

El resultado de todo, á más de la injustifica notoria y el perjuicio a los propietarios, es la fama del mal trato que en Costa Rica se dá á la inmigración asiática, para que no podamos conseguir brazos extranos, nosotros, que tanto carecemos de ellos". (El Ferrocarril. 14 de agosto de 1873: 3).

A manera de balance, se estaba ante una condición socio-laboral, en la cual el colectivo de trabajadores quedó al margen de prerrogativas y garantías que supuestamente el contrato les había conferido. En otras palabras, no hubo cumplimento efectivo de lo que se les había prometido; por el contrario, fueron víctimas de engaño, de condición de desprotección y explotación, próxima, sino igual, al que se ostentaba en régimen cuasi-esclavista:

"Aun recuerdo la impresión que me produjo la cuerda de chinos que ibamos a contemplar con curiosidad de público de circo. Comen con dos palillos el semicrudo arroz que sacan de una olla enorme, tienen trenza como las mujeres, duermen estimados en mal ajustadas y desnudas tablas; en sus miradas hay tristeza, tímida sorpresa, tal vez rubor del examen que su amo en ciernes les impone. Posible que hasta les examine los dientes como un mercado de yeguas. Y el amo después se llevaba uno, dos, o diez de esos ganados, y no fueron escasas las correcciones y otros aditamientos, al estilo de los tiempos del Tío Tom y su cabaña." (Pacheco, 1905: 24). 
Siguiendo con la idea anterior, esta se muestra también como ejemplo, cuando el grupo de trabajadores se ve afectado, más que cualquier otro trabajador que se desempeñara en labores iguales en la construcción de la vía del ferrocarril. Basta saber que las diferencias salariales se establecían hasta en un 50\% menos con respecto a demás trabajadores. Mientras que por cuatro horas laboradas, un chino recibía 0.13 reales, otros trabajadores de igual rango, recibían 0,54 reales, eso sino más (ANCR Serie Fomento: 8525).

En ese contexto, se puede decir que los chinos fueron víctimas de un degradante listón de abusos y vejámenes, que les afectó tanto en su calidad de trabajadores como en su dignidad de ser humano. Así fueron vendidos al mejor postor como si tratara de objetos y animales, pues la inescrupulosa y lucrativa "venta" de chinos acrecentada en el país, se tornó repugnante y motivo de severas críticas al nivel nacional e internacional. Al respecto, un grupo de diputados del Congreso de la República aseveró, por medio del informe presentado en 1874, que bajo el eufemismo de los contratos, lo que se efectuaba era una fructífera y descarada venta de "carne y huesos", semejante a la trata de negros en tiempos de la esclavitud. (ANCR-Serie Congreso: 8202, 1874) Al respecto, el representante diplomático de Washington se refirió de la siguiente manera:
"Se dice que los chinos que están en Costa Rica, bajo contrato de trabajo de ferrocarril, se venden como si estuvieran estatu libere o esclavos por cierto número de años. Llegaron a Costa Rica como trabajadores del ferrocarril con un contrato que estipulaba el tiempo y el salario y la condición de que serían regresados a su patria sin gasto para ellos. El tiempo de trabajo no ha expirado. El precio de cada chino se calcula según el lapso que están obligados a servir a su nuevo patrón por el tiempo que aún tienen que descontar." (De la Cruz, 1984).

\section{Reacciones de los trabajadores}

Todo lo anterior deja al descubierto la mala interpretación que realizaron patronos y empresarios de los contratos. En tanto, les consideraron instrumento legal que les concedía absoluto derecho sobre el trabajador. Vistos como objetos, creían tener derecho absoluto y como tal, asignarles valor monetario, venderles y transferirles a otra persona arbitrariamente, cuando se suponía que luego de ocho años por ser hombres libres, quedaban completamente emancipados (Moreno, 1989:238).

Dadas el conjunto de condiciones mencionadas, los chinos reaccionaron con una variedad de comportamientos: rebeldía, "cimarronaje", sumisión y hasta el suicidio. Con respecto al suicidio, el cuento "El Ahorcado", que forma parte de los Cuentos ticos, de Fernández Guardia, relata con ironía 
algunas de esas anécdotas macabras. Asimismo, en otras obras de la época, situaciones como las siguientes:

"Para las obras del ferrocarril se habian hecho venir culis de la China, con el objeto de ponerlos a trabajar en la zona mortifera, porque es bien sabido que la vida de un chino no tiene mayor importancia. $Y$ hay que suponer que ellos mismos debían de estimarlo así, considerando la facilidad con que se la quitaban. En efecto, no habia día en que no amaneciese algún hijo del $\mathrm{Ce}$ leste Imperio colgado de un árbol, para envidia de sus compañeros que a pie juntillo lo creían resucitado a orillas del Hoang ho, el famoso río Amarillo, y embelesado en la contemplación de las frágiles pagodas del país de Confucio, lejos del aborrecido capataz que los obligaba a trabajar (...)”. (Botey y Quesada, 1995: 57).

"Y aquellos infelices amarillos, que gemían por su lejana patria rompían sus cadenas arrójandose en las turbulentas aguas de las cataratas del Paraíso, porque creían despertar de su pesadilla entre las murallas de la remota China." (Pacheco: 24).

Como se indicó, las condiciones de trabajo provocaban también que los chinos huyeran de los campamentos y de otros lugares de trabajo. Sin embargo, para aquellos que no lograban con éxito su objetivo, la situación empeoraba pues, una vez recapturados, se les suministraba, a manera de castigo, la cantidad necesaria de latigazos y de hierros. Igualmente, no se permitía que fueran vendidos a nadie sin orden oficial y se les mantenía con cadenas hasta recibir órdenes pertinentes (Casey: 163) Al respecto reza cláusula II:

"Si alguno de los chinos fuere encontrado fuera de dichos campamentos o de los otros puntos de trabajo en la línea por primera $y$ por segunda vez, será aprendido y entregado a La Empresa a costa de a la tercera será también del mismo modo tomado y entregado a La Empresa, la cual cuenta propia, deberá hacerlo salir del país sin dilación." (Lao, 1993: 8-9)

Sin duda, la citada cláusula, dirigida mediante circular a los gobernadores de las provincias y administradores generales de comarcas, dictaba instrucciones expresas para que los chinos que se encontrasen en caminos y poblados no permitidos, fueran además de golpeados, remitidos a las casas, haciendas o campamentos respectivos. Una vez regresados a los lugares de trabajo, se exigía a patronos o responsables de los trabajadores a realizar indemnización de los gastos en que se había incurrido para su traída. (ANCR-Serie Gobernación: 33973). También se incluyó en una circular la prohibición de venta a los trabajadores de licores fuertes y de opio, justificándose los malos resultados que ocasionaban estas sustancias en su aptitud 
para el trabajo y conducta (ANCRSerie Gobernación: 2855).

\section{La huelga}

Hasta aquí hemos explicado una serie de situaciones laborales presentadas en el marco de la construcción de la vía del ferrocarril. Las mismas afectaron a trabajadores chinos y constituyeron un cúmulo de razones, para que se desencadenara en un verdadero conflicto laboral. Las causas se entienden cuando en calidad de trabajadores contratados se les violenta e incumple el conjunto de derechos que supuestamente se les había garantizado.

Dadas esas condiciones, el colectivo de trabajadores decidió de común acuerdo hacer cese de las tareas que tenían encomendadas, el día 5 de enero de 1874 , todo con el fin de presionar e imponer la aceptación de las condiciones a los patronos. La situación se agrava cuando la empresa, sin ninguna consideración, hace un llamado obligatorio a trabajar el día siguiente. Si bien en principio no estaban obligados a hacerlo por ser un día festivo de reyes, cuenta también que las condiciones adversas del clima hacía prácticamente imposible laborar.

Ante los acontecimientos suscitados, la empresa del ferrocarril pidió al Gobernador de la Provincia de Cartago enviar tropas para contener la revuelta de los 150 huelguistas. Para esto se envió una fuerza militar de 35 guardas al mando de un señor de apellido Chinchilla, quien se aseguró llegó al lugar en un estado completo de embriaguez y, despóticamente, arremetió contra los huelguistas (ANCRSerie Gobernación: 27692). Resultado del grave incidente, perecieron seis chinos, siete trabajadores heridos y varios aprehendidos de algunos campamentos de zona del Reventazón (ANCR - Serie Fomento: 205, 1874).

La forma utilizada por las tropas para aplacar el movimiento fue tan brutal, que el mismo Salvador Lara, Director General del Ferrocarril, solicitó al Secretario de Estado, nombrar con carácter de urgente una comisión encargada de investigar y rendir informe detallado de los hechos ocurridos (ANCR - Serie Fomento: 205, 1874) Al cabo de unos cuantos días, el informe no solo confirmó la resistencia pacífica que habían mostrado los trabajadores sino la brutal paliza que habían propinado las tropas a los mismos, que en su mayoría aún dormían (De la Cruz, 1984: 32):

"Corrientemente que el día en que se resistieron los chinos á acudir al trabajo, conocidos en los Países Católicos por el nombre de Día de Reyes, era un día festivo entre ellos ..." (ANCR - Serie Fomento: 205, f.8, 9 enero 1874).

“...que no eran una tropa comedida y respetable sino una turba de desafiadores salvajes, al mando de 
un tiranuelo más familiar con la intemperancia que con la disciplina y la ciencia militar." (ANCR - Serie Fomento: 205, f.8, 9 enero 1874).

En síntesis, quedó completamente claro que en el conflicto ocurrido en enero de 1874, la tropa fue la única responsable de los muertos y heridos que se sucedieron en los campamentos. Tanto por el saldo trágico como la forma en que se dio, las críticas al gobierno de Costa Rica transcendieron las fronteras, repercutiendo en severas afrentas al nivel internacional, tal y como refiere el artículo periodístico titulado Matanza de Chinos en Costa Rica:

"Tenemos conocimiento de algunas publicaciones que ha hecho la prensa extranjera, en las cuales se trata de acriminar á Costa Rica, con motivo del desgraciado acontecimiento que tuvo lugar en Fébrero último, en una de las estaciones del ferro-carril, y que dio por resultado la muerte de algunos chinos, de los que fuesen contratados para trabajar en el camino.

Justo y loable nos parece la censura de un hecho que nosotros hemos sido los primeros en deplorar, no solo por el respeto que nos inspira la vida humana, sino por las consecuencias que él podía causar en detrimento de una empresa, como la del ferro-carril, por lo que el silencio que ha guardado la prensa del país sobre este asunto, han dado márgen á la implícita recriminación contra el gobierno..." El Costarricense. 10 de marzo de 1874: 1).

Ahora, pese a todas las críticas que tuvieron lugar, las mismas no alcanzaron al parecer efecto alguno en la mejoría de las condiciones y trato de los trabajadores. Así, un año después, se nota un recrudecimiento y la persistencia de escenas que delatan la pésima situación de los trabajadores.

"En la tarde del sábado 14 del corriente tuvimos ocación de presenciar en la estación del Ferrocarril en esta ciudad un hecho que revela, un espíritu egoista, indudable y criminal .

Pocos momentos antes de la salida del tren fue llevado á la estacion un asiático bajo la custodia de dos soldados y algunos particulares; inmediatamente dispuso un señor, allí presente, que se le pusiese un grillo con cadena ...

Los soldados condujeron á la víctima a sentarle en la linea y alli sobré unos de los rieles á la presencia de un polícia con el auxilio de los soldados de Costa-Rica le fue ignominiosamente remachado el grillo en un pié á un súbdito de S.M. el Emperador de la China, embarcado luego con dirección a San José.

Algunas personas presentes murmuraron de la ilegalidad, abuso y atropello de aquel acto, por el Señor que lo habia asi ordenado, replicó ser aquel chino su propiedad y por lo tanto poder hacer con él lo que 
creyeran conveniente para la seguridad de su pertenencia, y que él no podía perder el dinero que había empleado en la "compra"...

En Costa Rica, República democrática, se trata de esclavizar á los chinos.

Tengan entendido los patrones que el desembolsar su dinero por el traspaso del contrato, no adquieren el más mínimo derecho sobre la persona del asiático, sino únicamente el trabajo o del mismo por el tiempo estipulado en el contrato." (El Ferrocarril. 27 de agosto de 1875:1).

Cabe mencionar que las deplorables condiciones de los trabajadores chinos no fue asunto exclusivo de Costa Rica. Así pululan, en otros países del continente, las horrendas historias que se refieren también a la "matanza de chinos". Por esta y otras razones, el imperio Manchú estimó conveniente abrir tantas sedes consulares y embajadas como fueran necesarias en diferentes países de América, con el fin de proteger los derechos violentados de sus conciudadanos.

Consecuentemente, también aparecieron una serie de agrupaciones de inmigrantes chinos, donde la cohesión como grupo sobrepasó el carácter informal que tenían. El norte principal de la organización se enfocaba en intervenir y evitar eventuales discordias entre los socios, y asimismo un medio que sirviera para protegerse y auxiliarse mutuamente de las adversidades que afrontaban en los lugares a los que llegaban.

En tanto, a fines del siglo XIX $\mathrm{y}$ principios del $\mathrm{XX}$, se extendieron, por todo el continente americano, diferentes asociaciones conformadas por inmigrantes chinos que, bajo la influencia de los preceptos de filosofías orientales, ostentaban dentro sus postulados la solidaridad con demás paisanos. Esta idea arraigada constituyó, a la postre, un factor determinante, por el cual muchos adquirieron éxito económico y elemento para auto identificarse como grupo diferenciado.

Es precisamente en Panamá, en 1882, cuando se tiene dato del surgimiento de la primera sociedad de beneficencia china organizada, llamada Way On, misma que fue reorganizada en 1904, y cambiada de nombre por el de Beneficencia China (Mon: 253). Igual destacan otras agrupaciones de este tipo como The Chinese Consolidade Benevolent Association fundada en Nueva York en 1883 y la de Vancouver en 1884, Perú en 1885, Portland en 1886 y Seattle en 1887, además de La Unidad China Asociada de Honolulu, fundada en 1883. Esta última es famosa por reunir a los diferentes inmigrantes de origen chino, por dialectos y religión, tiempo en que también se crea el consulado, con el objetivo de defender a los chinos radicados en ese lugar (Chan: 6). 


\section{Conclusiones}

Los trabajadores chinos fueron estigmatizados de manera negativa durante el desarrollo natural de los países a los cuales llegaban. Así Costa Rica no fue la excepción y dentro de la dinámica socio-laboral de la construcción de la vía del ferrocarril al Atlántico, fueron marginados de prerrogativas y garantías de que gozaban otros trabajadores.

En vista de ello, dichos trabajadores no solo mostraron que eran pasivos y respetuosos de la sociedad a la cual llegaban, sino también personas que sabían mantener y defender su dignidad. Así el colectivo acude a la confluencia de símbolos y rituales de su cultura como recurso identitario, pero también contribuyen a fortalecer la conciencia de grupo.

No obstante, como trabajadores perjudicados no quedó más que hacer uso de la huelga, para tratar de imponer la aceptación de las condiciones laborales a los patronos. Ahora, la importancia de la misma no solo debe mirarse en un marco simplista y romántico, que exalte la valentía de un grupo de trabajadores que deciden hacer valer sus derechos.

Así debe recordarse por sus características, como el primer movimiento reivindicativo y conflicto obrero patronal que aconteciera en Costa Rica. Más que ello, las odiosas prácticas propias de un régimen cuasiesclavista, que a finales de siglo
XIX se evidencia en el país y demás del continente.

Que la "matanza de chinos" y sus consecuencias, en páginas oscuras en la historia costarricense, no continué en el vil de los olvidos. Por el contrario, el inició de subsiguientes luchas que enarbolaron muchos trabajadores y próceres de la patria para consolidar los grandes logros que nosotros hoy tenemos, debe sewr el norte de este y otros escritos al respecto.

\section{Bibliografía}

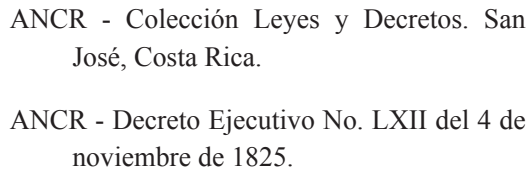
José, Costa Rica.

ANCR - Decreto Ejecutivo No. LXII del 4 de noviembre de 1825 .

ANCR - Serie Congreso: 9548.

ANCR - Serie Congreso: 8202, 1874.

ANCR - Serie Fomento: 205, f.8, 9 enero 1874.

ANCR - Serie Fomento: 217. Folio 1.

ANCR - Serie: Fomento 1634, f. 303, 28 de mayo de 1873 .

ANCR - Serie: Fomento doc: 1531, f.114-115, dic 1873;

ANCR - Serie: Fomento 1634, f. 295, 15 de mayo 1873.

ANCR - Serie Fomento: 8525.

ANCR - Serie Fomento: 205, 1874

ANCR - Serie Gobernación: 27692

ANCR - Serie Gobernación: 33973. 
ANCR - Serie Gobernación: 2855.

ANCR - Serie Gobernación: 34334

ANCR - Serie Gobernación: 12043. 1897

ANCR - Serie Gobernación: 7963. Folio 3.

ANCR - Serie Gobernación: 34334.

ANCR - Serie Policía: 5651.

Botey, Ana María y Quesada, Juan Rafael (1995). "Introducción Histórico-Social". En Antología: "Formacion Ciudadana 3". Universidad de Costa Rica.

Brinley, Thomas (1991). "Migración Internacional y Desarrollo Económico". Revista de la U.N.E.S.C.O.

Casey Gasper, Jeffrey. "La Inmigración China". En: Revista de Historia de la Universidad Nacional. $\mathrm{N} .{ }^{\circ} 1$.

Chan, Sucheng. Asian Americans. An interpretive history. Twayne publishers. Nueva York. 1991.

Chen Apuy, Hilda. Entrevista realizada 28 de agosto de 1999. "Chinese Migrants in Central and Eastern Europe: The Causes of the Czech Republic, Hungary and Romania." Revista de la Organización Internacional para la Migración (OIM). Sep. 1995.

De la Cruz de Lemos, Vladimir (1984). Los Hechos Sociales en Costa Rica 18701930. Editorial Universidad de Costa Rica, San José, Costa Rica.

El Costarricense. 10 de marzo de 1874.

El Ferrocarril. 27 de agosto de 1875.

El Ferrocarril, 11 de setiembre de 1873.

El Ferrocarril. 14 de agosto de 1873.
Fallas. Antología Formación Ciudadana.

Gómez Izquierdo, José Jorge. México, 1991

Howe, Irving (1976). World of our Fathers, a Touchstone Book. New York.

Kim, Elaine. Lao Obando, Juan José. ¿Fuimos Esclavistas? La Inmigración China en Costa Rica . Sinorama de Costa Rica. San José, Costa Rica. Mayo de 1993.

León, Moisés. The Chinese of Costa Rica. Summary to the world. Cultures enciclopedia. San José, Costa Rica. 1991.

Martínez Montiel, Luz María y Reynoso Medina. (19939 Inmigración Europea y Asiática Siglos XIX y XX. Fondo Nacional para la Cultura y las Artes y el Fondo de Cultura Económica. 1ra. Edic. México, DF.

Mesa, Roberto (1967). El Colonialismo en la Crisis del Siglo XIX Español. Ciencia Nueva. Madrid, España.

Mon Pinzón, Ramón A. "La Migración China a Panamá". En: Europa, Asia y Africa en América Latina y el Caribe.

Montealegre, Mariano (1895) "La inmigración en Costa Rica." La República. San José, Costa Rica.

Moreno Fraginals, Manuel R. (1989) "Migraciones Chinas a Cuba 1848-1859". En: Europa, Asia y África en América Latina y el Caribe. Editorial Siglo Veintiuno. México.

Mörner, Magnus (1978). "La Inmigración desde Mediados del Siglo IX: Una Nueva América Latina". Revista Culturas. Vol. 3. UNESCO.

Oliva Medina, Mario (1992). "Movimientos Sociales en Costa Rica 1825-1930. 
En Revista: Nuestra Historia N. $^{\circ} 13$. EUNED.

Pacheco, Leonidas (1905). Algunos Apuntes sobre Inmigración. Tipografía Nacional.

Pérez de la Rica (1974). "Contribución a la Historia de la Gente sin Historia”. Revista de Ciencias Sociales. La Habana, Cuba.
Revista de la Organización Internacional sobre las Migraciones (OIM) en América Latina. Vol. 12. № 1/3. Abril -Diciembre de 1994.

Verne, Julio (1996). Las Tribulaciones de un Chino en China. Editorial Porrúa. SA. 11 Edic. México. D. F. 